imagen del Creador, digna de participar en la santa Eucaristía, [...] pero no sería, sin embargo, digna de las excelencias y de los privilegios del hombre". Aquest esquema de raonament sobre la igualtat en valor dels sexes i sobre la capacitat de les dones és el que ha anat perdurant $i$, a partir de la Il-lustració, segueix fins als nostres dies amb els pertinents canvis i adaptacions als temps.

Marie de Gournay comparteix raó i sentiment en el seu discurs i resulta contrastant la sensibilitat en l'expressió de les seves idees enfront dels discursos dels homes que menyspreen, exclouen les dones en general i desautoritzen especialment les dones cultes i erudites com ella. El seu sentiment dolorós enfront de la injustícia es fa evident, per exemple, en el començament del tractat Agravio de damas (1626), que diu: "Bienaventurado eres tú, lector, si no perteneces al sexo al que se le prohíben todos los bienes, privándole de la libertad; al que incluso se le prohíben casi todas las virtudes, alejándolo de cargos, oficios y funciones públicas".

Pel que fa als textos Apología de la que escribe i Copia de la vida de la doncella de Gournay és interessant veure com Marie de Gournay, com també passa en moltes altres autores, parteix de la seva pròpia experiència i ens ofereix un sentit testimoni que reforça la convicció del seu pensament. L'autora busca afermar la seva autoritat $i$, a partir del seu cas particular com a dona que cerca regir la seva pròpia vida, generalitza les seves expectatives i argumenta a favor de la dignitat i de les capacitats de tot el gènere femení. Aquests textos són posteriors als anteriors, el que ens fa veure la necessitat d'explicar-se ella mateixa i explicar-se al altres amb afany de justificació, però també amb la satisfacció d'haver assolit els seus propòsits.

Per acabar cal subratllar que es tracta d'una edició molt acurada, fruit del bon treball en equip de les traductores que també són les que elaboren una introducció amb notes molt exhaustiva. Es completa amb un útil índex de noms propis i la bibliografia pertinent. L'edició compta fins i tot amb il-lustracions interessants i significatives com el retrat de l'autora o una mostra de les seves notes manuscrites a l'edició de Montaigne. Evidentment era l'edició que es mereixia Marie de Gournay.

MERCĖ OTERo VidAL merceoterovidal@gmail.com

\title{
Trans ${ }^{\star}$ exualidades. Acompañamiento, factores de salud y recur- sos educativos
}

Raquel (Lucas) Platero Méndez

Barcelona, Edicions Bellaterra, 2014, 440 pp. ISBN: 978-84-7290-688-4 
Las investigaciones realizadas en España en torno al travestismo, la transexualidad y los transgenerismos han ganado peso, en los últimos años, gracias a diversas aportaciones que han conseguido aproximar dos esferas a menudo alejadas, cuando no antagónicas: el activismo y la academia. Los trabajos de Gerard Coll-Planas, Miquel Missé, Norma Mejía, José Antonio Nieto Piñeroba y Raquel (Lucas) Platero Méndez, entre otrxs autorxs, han ofrecido aproximaciones muy variadas pero que comparten el objetivo de iluminar un conjunto de experiencias, identidades y cuerpos situados al margen de los binarismos dominantes (masculino/femenino, heterosexual/homosexual), a partir de los testimonios de lxs propixs sujetos implicadxs.

A diferencia de otros trabajos orientados a la reflexión teórica, Trans $^{*}$ exualidades se distingue por su voluntad de intervenir efectivamente en la realidad de las personas trans ${ }^{*}$ y de sus diferentes ámbitos (familiares, educativos, laborales). Platero Méndez señala que se trata de "una propuesta transformadora hecha a partir del saber y con las experiencias de sus protagonistas" (11). En este sentido, la utilización de un lenguaje claro y accesible, incluso cuando se abordan conceptos y problemáticas de indudable complejidad, constituye un logro notable. Que la mayor parte de las citas correspondan a testimonios, tanto de personas trans* como de familiares o profesionales que trabajan con ellxs, muestra a las claras que la apuesta consiste en tender puentes desde la investigación académica hacia la experiencia cotidiana de quienes desafían las normas de sexo y género, a fin de aclarar nociones básicas, desterrar prejuicios y evitar situaciones de violencia y discriminación.

El libro se organiza en dos grandes bloques. El primero, titulado “Trans*exualidades" (pp. 41-274), desarrolla, a lo largo de cuatro apartados, cuestiones teóricas y conceptuales. “¿Qué es la transexualidad?” (pp. 41-178) deslinda nociones clave - travestismo, homosexualidad, transexualidad, transgenerismo- y realiza una importante contribución al debate con la propuesta del concepto "trans*", que si bien abarca diferentes expresiones e identidades de género, también señala, a través del asterisco, la heterogeneidad y los posibles disensos entre quienes se identifican como trans, transexuales o transgéneros. Este apartado introduce, además, una minuciosa descripción sobre los distintos procesos - desde la infancia hasta la adultez - que atraviesan las personas que no se identifican con el género asignado al nacer. Platero Méndez defiende la necesidad de atender las manifestaciones de disidencia incluso cuando se trata de niñxs y adolescentes, aunque insiste en que conviene evitar la imposición de etiquetas pues no todas las personas de género flexible o creativo resuelven iniciar una transición hacia otro/s género/s. El apartado "Factores de salud y protección” (pp. 179-209) ofrece recomendaciones para acompañar y proteger a las personas trans*, apostando por la existencia de entornos sin transfobia; en este sentido, se subraya la importancia de propiciar "escuelas seguras" y favorecer el contacto entre personas trans ${ }^{\star}$ de diferentes franjas 
etarias. “Transfobias" (pp. 210-230) aborda la prevención de distintas formas de violencia y pone el acento en el reconocimiento del valor positivo de la diversidad (y no en la mera tolerancia); muestra, además, que la transfobia no es un fenómeno individual sino también institucional, por lo que resulta imprescindible poner en marcha múltiples estrategias para modificar la percepción cultural de las personas trans*. "En primera persona" (pp. 231-274) cierra el primer bloque presentando testimonios de menores, jóvenes y adultos trans ${ }^{\star}$, así como de familiares y profesionales que intervienen en su acompañamiento.

El segundo bloque se inicia con un apartado, "Técnicas para la intervención" (pp. 275-358), en el que se proponen diferentes actividades para el ámbito educativo, acompañadas de fichas que facilitan su realización. "Algunos referentes del pasado" (pp. 359-378) contiene seis biografías de personalidades españolas, desde la célebre Monja Alférez (Catalina de Erauso) a Teresa / Florencio Pla Meseguer, que desafiaron — en otros contextos sociales e históricos- las rígidas normas de sexo y género. Finalmente, en el apartado "Algunos recursos recomendados” (p. 379-394), Platero Méndez sugiere documentales, cortometrajes, películas, literatura infantil y juvenil, novelas y ensayos que pueden ser de utilidad para abordar pedagógicamente el tratamiento de temas trans ${ }^{\star}$. Cada material recomendado incluye una breve descripción. Cierran el volumen un "Glosario" (pp. 399-412) de términos y conceptos ampliamente tratados en el primer bloque, así como una extensa y actualizada "Bibliografía” (pp. 413-434).

Trans $^{\star}$ exualidades constituye, en definitiva, un rico y valioso aporte a los estudios trans* españoles, pues recapitula con concisión y claridad aspectos teóricos y conceptuales, a la vez que brinda propuestas específicas para acompañar y favorecer el empoderamiento de las personas que transgreden los géneros normativos. La focalización en los entornos opresivos, los tratamientos médicos y psicológicos adversos y las legislaciones discriminatorias contribuye a dotar de protagonismo a las personas trans*, desplazando así el "conflicto" de sus cuerpos, deseos y comportamientos hacia diferentes instancias sociales e institucionales que obstaculizan su pleno desarrollo.

JoRge Luis PERALTA jperalta@fahce.unlp.edu.ar 